\title{
Small-Scale Spatial Gradients in Climatological Precipitation on the Olympic Peninsula
}

\author{
Alison M. Anders* And Gerard H. Roe \\ Department of Earth and Space Sciences, University of Washington, Seattle, Washington \\ Dale R. Durran and Justin R. Minder \\ Department of Atmospheric Sciences, University of Washington, Seattle, Washington,
}

(Manuscript received 25 September 2006, in final form 11 December 2006)

\begin{abstract}
Persistent, 10-km-scale gradients in climatological precipitation tied to topography are documented with a finescale rain and snow gauge network in the Matheny Ridge area of the Olympic Mountains of Washington State. Precipitation totals are $50 \%$ higher on top of an $\sim 800$-m-high ridge relative to valleys on either side, $10 \mathrm{~km}$ distant. Operational fifth-generation Pennsylvania State University-NCAR Mesoscale Model (MM5) runs on a 4-km grid produce similar precipitation patterns with enhanced precipitation over high topography for 6 water years.

The performance of the MM5 is compared to the gauge data for 3 wet seasons and for 10 large precipitation events. The cumulative MM5 precipitation forecasts for all seasons and for the sum of all 10 large events compare well with the precipitation measured by the gauges, although some of the individual events are significantly over- or underforecast. This suggests that the MM5 is reproducing the precipitation climatology in the vicinity of the gauges, but that errors for individual events may arise due to inaccurate specification of the incident flow.

A computationally simple model of orographic precipitation is shown to reproduce the major features of the event precipitation pattern on the windward side of the range. This simple model can be coupled to landscape evolution models to examine the impact of long-term spatial variability in precipitation on the evolution of topography over thousands to millions of years.
\end{abstract}

\section{Introduction}

Mountains strongly influence the spatial distribution of precipitation at the earth's surface. Review summaries of orographic precipitation processes can be found in Smith (1979), Barros and Lettenmaier (1994), and Roe (2005). The majority of orographic precipitation studies have focused on single events or small numbers of events often from intensive, short-term field measurement programs. In contrast, relatively little attention has been paid to climatologial patterns of precipitation for spatial scales smaller than entire mountain

* Current affliation: Department of Geology, University of Illinois at Urbana-Champaign, Urbana, Illinois.

Corresponding author address: Alison M. Anders, Department of Geology, University of Illinois, 1301 West Green St., Urbana, IL 61801.

E-mail: amanders@uiuc.edu

DOI: $10.1175 / J H M 610.1$

(C) 2007 American Meteorological Society ranges. Long-term, high-spatial-resolution records of precipitation in mountains are rare. The difficulty of measuring snowfall and the dearth of precipitation gauges in mountains, especially at high elevations, contribute to the problems of monitoring climatological mountain precipitation.

The data that are available on climatological patterns of mountain precipitation suggest remarkable spatial variability in precipitation at small scales. The European Alps, unlike most mountain ranges, are covered by a relatively dense rain gauge network. In the Alps, there are regions in which annual precipitation varies by a factor of 2 over spatial scales of less than $50 \mathrm{~km}$ (Frei and Schär 1998). These precipitation gradients are not the result of a rain shadow in the lee of the range as a whole; rather, they occur along the southern flank of the range and are associated with smaller-scale topographic features (Frei and Schär 1998). Across the Himalayas, precipitation gradients at a $10-\mathrm{km}$ resolution from a 4-yr record of satellite precipitation radar 


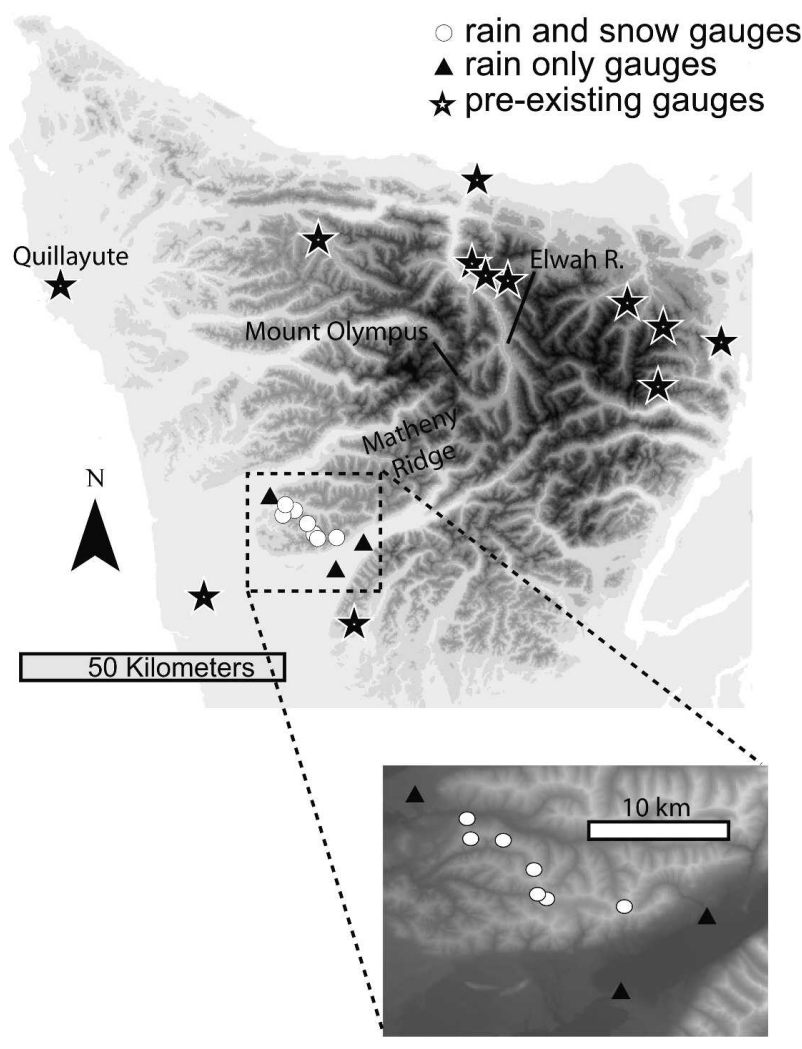

FIG. 1. The locations of rain gauges and rain/snow gauges installed for this study are marked with black triangles and white circles, respectively. Rain and snow gauges that regularly report as part of the NWS/FAA, RAWS, COOP, and SNOTEL networks are shown as black stars. Radiosondes are launched from Quillayute. (lower) Detail of the region where gauges were installed.

measurements reveal fivefold variation in precipitation over scales of $40 \mathrm{~km}$ between large river valleys and adjacent ridges (Anders et al. 2006). Are such gradients in climatological precipitation a common feature in mountain ranges? How do they arise? In working toward general answers to these questions, we consider the specific case of the Olympic Mountains of Washington State (Fig. 1).

The focus of this paper is on documenting spatial variability in climatological precipitation on the scale of ridges and valleys. The primary dataset comes from rain and snow gauge observations that are used to constrain the long-term precipitation pattern on the windward side of the Olympic Peninsula. Two models that differ vastly in their complexity are used to provide context for the gauge observations. Operational forecasts from a state-of-the-art mesoscale weather prediction model [the fifth-generation Pennsylvania State University-National Center for Atmospheric Research Mesoscale Model (MM5)] allow for consideration of a longer time period (6 water years) than the gauges alone. In addition, the precipitation forecasts provide a view of precipitation over the entire Olympic Peninsula. A simple linear orographic precipitation model provides an idealized precipitation pattern produced with linear physics to compare with the gauge observations. A detailed diagnosis of the behavior of MM5 in this region, while meriting further research, is beyond the scope of this paper. Likewise, the linear model is not examined in detail for individual cases; rather, it provides a qualitative benchmark for consideration of the precipitation mechanisms that dominate over climatological time scales.

\section{Precipitation patterns in the Olympics}

The Olympic Mountains receive abundant precipitation with more than $3 \mathrm{~m} \mathrm{yr}^{-1}$ measured in the Hoh River valley on the western side of the range. There is a pronounced rain shadow with only $0.4 \mathrm{~m} \mathrm{yr}^{-1}$ of precipitation in Sequim on the northeastern corner of the Olympic Peninsula (Thomas et al. 1999). Orographic precipitation in the Olympics has already received considerable study (Parsons and Hobbs 1983; Barros and Lettenmaier 1993; Colle and Mass 1996; Cole et al. 1999; Leung and Qian 2003). In addition, precipitation in this region has been forecast at 4-km resolution with the MM5, a numerical weather prediction model, since 1997 (Mass et al. 2003).

Two datasets are used to assess the long-term precipitation pattern in the Olympic Mountains: archived MM5 modeled precipitation and a small-scale rain and snow gauging network established in the vicinity of Matheny Ridge on the southwestern side of the Olympic Peninsula as shown in Fig. 1. The datasets are analyzed at annual and seasonal time scales, using water year totals for the MM5 forecasts and wet-season totals for the gauge network. A shorter time scale of 2-5 days, typical of storm events, is also examined using both forecasts and gauges. The results are presented beginning with a description of the MM5 dataset and the yearly precipitation patterns from MM5. Then the gauge network is discussed along with an analysis of gauging error. The gauge data are shown first at a seasonal time scale and compared to MM5 predictions at the gauge locations. Finally, a set of the 10 largest events of the 2003-04 wet season, as measured and modeled, are described in more detail.

The MM5 is run operationally at the University of Washington in conjunction with the Northwest Modeling Consortium (Mass et al. 2003). The MM5 is run twice daily with nested grids of 36-, 12-, and 4-km horizontal resolution. The 36- and $12-\mathrm{km}$ domains of the model are initialized at 0000 and 1200 UTC and run for 

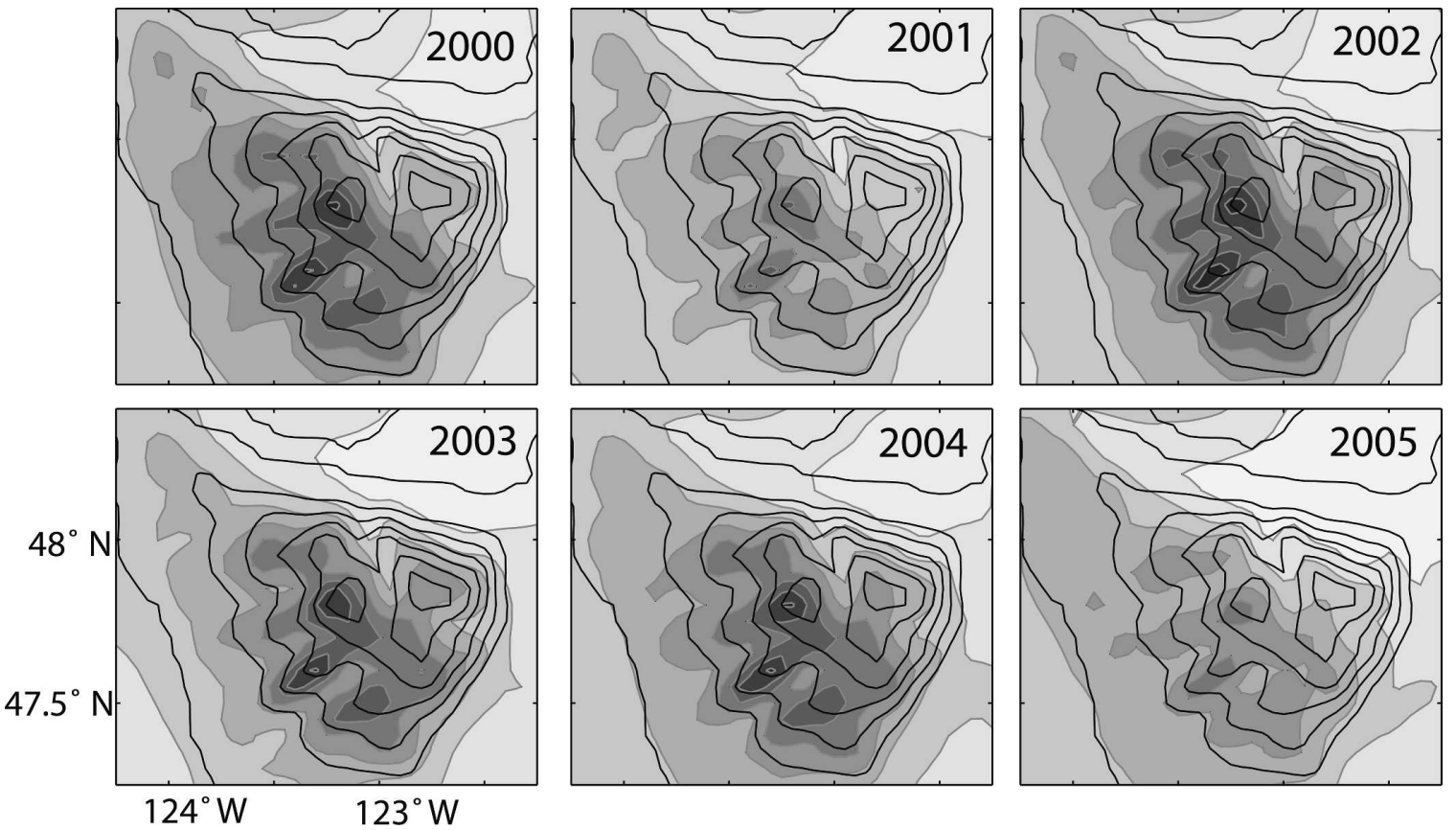

FIG. 2. Annual MM5 precipitation forecast totals for water years 2000-05 are shown in gray shading with a contour interval of $750 \mathrm{~mm} \mathrm{yr}^{-1}$. Topography is contoured at $250-\mathrm{m}$ intervals in black.

$72 \mathrm{~h}$. At forecast hour 6 the 4-km domain is initialized with output from the 12-km domain and run until forecast hour 48 . We define surface precipitation that accumulated in the 4-km domain between forecast hours 24 and 36 as the precipitation total for each run. These 12-h precipitation totals were summed to define annual and event totals from MM5. Over 99\% of model runs have been included in the analysis. Six water years (1 October-30 September) were considered beginning in October 1999 and continuing through September 2005.

Over the time frame considered, the operational MM5 forecasts underwent several changes to the model grid and physics options. The details of these changes are available online at http://www.atmos.washington. $\mathrm{edu} / \mathrm{mm} 5 \mathrm{rt} / \mathrm{info} . \mathrm{html}$. Changes to the grid necessitate interpolation of modeled precipitation to a common grid. Summation was done in the native grid for the time period that each grid was used and then interpolated onto a regular latitude-longitude grid for comparison. There have also been several changes to the physics options used in the 4-km domain and the largerscale domains that provide input for it. Most importantly, the ice microphysics was changed from the simple ice parameterization to the Reisner 2 option in February 2004, and the Kain-Fritsch cumulus parameterization was turned on in the 4-km domain in August 2004.
As is apparent in Fig. 2, the 6 years modeled are very similar in the spatial pattern of precipitation predicted on the annual time scale. The term "spatial pattern" is used herein to refer to the relative difference in precipitation amounts across space. Spatial patterns are independent of the amount of area-averaged precipitation, and as a consequence, spatial patterns of precipitation accumulated over different time scales can be directly compared. In all the years studied the locations of the precipitation minima and maxima are the sameridges on the southwest side of the range are consistently forecast to receive 1.5 to 3 times as much precipitation as neighboring valleys only $10-15 \mathrm{~km}$ away. On the northeastern, typically downwind, side of the range, there is a rain shadow relative to the southwest side and a dry slot in the Elwha Valley sitting just to the west of the highest topography in the range: Mount Olympus (Figs. 1 and 2).

The pattern predicted by MM5 remains remarkably constant despite interannual variability in the areaaveraged precipitation and changes to the model physics. Annual area-averaged forecast precipitation on Olympic Peninsula (extent shown in Fig. 2) varies from $1870 \mathrm{~mm}$ in water year 2001 to $2369 \mathrm{~mm}$ in water year 2000. This modeled variability between years is confirmed in gauged precipitation totals from the region. However, the spatial pattern of precipitation is essentially constant from year to year (Fig. 2). This is con- 
sistent with the observation that mean flow in this region is not highly variable from year to year. Changes to the model physics were made during water year 2004. Despite these changes, the spatial pattern of precipitation does not change significantly (Fig. 2). Analysis of the archived and new high-resolution MM5 simulations (which will be described in a subsequent paper) show that warm-rain processes, particularly the collection of cloud droplets by rain, are primarily responsible for the rainfall enhancement along the ridges; this appears to account for the insensitivity of the MM5 precipitation forecasts to the ice microphysical parameterization.

As the small-scale pattern of precipitation presented above is a model result, it is important to evaluate the accuracy of the prediction. Previous analyses of precipitation in the Cascade Mountains to the east of the study area suggest that, on the scale of the entire range, MM5 4-km operational runs have a tendency to overpredict precipitation totals on high-elevation windward slopes and to underpredict totals in the lee of high topography (Colle et al. 2000). The extent of over prediction is difficult to determine because of the large undercatch errors associated with gauging snowfall. However, Colle et al. (2000) argue that undercatch by snow gauges alone is not sufficient to bring MM5 and the gauge record into agreement as forecast precipitation was $160 \%-250 \%$ of measured while undercatch estimates vary from $15 \%$ to $45 \%$ of total precipitation. In contrast, underprediction of MM5 precipitation totals in a westward draining basin of the Washington Cascades during a rain-on-snow event was shown to negatively impact real-time hydrograph prediction (Westrick and Mass 2001).

In the Olympic Mountains a lack of precipitation gauges (Fig. 1) hampers evaluation of MM5's accuracy. Data from the preexisting gauges that were present in the Olympics suggested the opposite effect of that seen in the Cascade Mountains, namely, underprediction by MM5 on the south and southwestern windward facing slopes and slight overprediction by MM5 in the lee on the northeast corner of the range (Colle et al. 2000). A case with southwesterly flow toward the Olympics was studied during the Coastal Observation and Simulation with Topography field experiment (Bond et al. 1997). This case was modeled with MM5 at a 3-km resolution revealing that MM5 simulated realistic flow structures and model precipitation totals were within $30 \%$ of the storm totals recorded at the majority of gauges in the region (Colle and Mass 1996). This result suggests that MM5 at 4-km resolution has the potential to reasonably simulate precipitation processes on the Olympic Peninsula. During the IMPROVE 2 field campaign, highresolution MM5 forecasts of dynamical and microphysi- cal fields were compared with detailed aircraft and radar observations over the Oregon Cascade Mountains. Using 4/3-km horizontal resolution, the model was able to effectively simulate observed variations in radar reflectivity, cloud water, and vertical velocity that were tied to individual ridges and valleys for the 13-14 December 2001 case (Garvert et al. 2005a,b, 2007). Modeled precipitation rates at the ground were strongly modulated over individual ridges $\sim 10 \mathrm{~km}$ in width; however, the lack of a dense gauge network prevented a detailed verification of MM5's high-resolution precipitation forecast on these scales Garvert et al. (2007).

To better constrain the reliability of MM5's prediction of repeated small-scale precipitation gradients, we established a finescale rain and snow gauge network in a region predicted by MM5 to have very large spatial gradients in annual precipitation: the southernmost of the large ridges on the southwestern side of the range in the vicinity of Matheny Ridge (see Figs. 1 and 2). This area is part of Olympic National Forest and logging activity in the last few decades has provided both clearings suitable for placing rain and snow gauges and access roads into the area. In October of 2003, 10 gauge sites were established in a rough transect across the predicted precipitation gradients (Fig. 1). At elevations below $200 \mathrm{~m}$, tipping-bucket rain gauges with $0.2-\mathrm{mm}$ resolution were installed. At elevations above $200 \mathrm{~m}$, gauges designed to measure both rain and snow were installed. The gauges were removed in May 2004 and slightly modified gauges were reinstalled at the same locations along with several additional sites in September 2004. We focus on the data collected between October 2003 and May 2004 to evaluate the season totals and storm events. Data from the second and third seasons (November 2004-April 2005, October 2005March 2006) are used to compute season totals for comparison. Less than $20 \%$ of the annual precipitation recorded at Quillayute falls from May to September, indicating that the gauging season records the majority of annual precipitation.

The reliability of the measurements, especially from the snow gauges was a concern in the design of the experiment. The difficulty of measuring snow and snow water equivalent has been discussed by many authors (e.g., Wilson 1954; Dingman 1994; Groisman and Legates 1994; McCaughey and Farnes 1996; Ferguson et al. 1997; Yang et al. 1998; Caracoana and Enz 2000) and errors of $30 \%$ in monthly totals are common. The rain and snow gauges we used are similar in design to the gauges described by McCaughey and Farnes (1996) and later produced by Campbell Scientific as snow adaptor CS705. The gauges studied by McCaughey and Farnes (1996) were found to agree with other methods 
of gauging snow to within $\sim 10 \%$. The gauges consist of a reservoir filled to a constant level with an overflow pipe feeding into a tipping-bucket gauge with $1-\mathrm{mm}$ resolution. The reservoir is filled with a $50-50$ mixture of ethanol and propylene glycol ("bio-friendly" antifreeze) with a thin layer of mineral oil on the surface to inhibit evaporation. When rain or snow falls into the reservoir, fluid from the bottom of the reservoir is displaced into the tipping-bucket gauge. The solution has a low freezing point, a density very close to that of water, and water is miscible with the solution. Therefore, over time the solution becomes diluted by the precipitation, and the reservoir must be replenished. Based on observations of the amount of precipitation in the first two seasons, we concluded that the antifreeze mixture can quickly become too dilute due to the large precipitation totals at our sites. As a result, no antifreeze was used during third season of gauging. ${ }^{1}$

To determine if the network would be capable of resolving the pattern of interest, the accuracy of the gauges was compared to the size of the predicted difference in precipitation between the stations. Two measures of spatial variability in precipitation are defined: the ridge-valley ratio is the average precipitation at the stations above 260 -m elevation divided by the average precipitation at stations below $160-\mathrm{m}$ elevation and the maximum-minimum ratio is the ratio of the maximum precipitation at a ridge station divided by the minimum precipitation at a valley station. The MM5 forecast patterns for annual totals and 10 large precipitation events in water years 2000 and 2001 have ridge-valley ratios of 1.3-1.8 and maximum-minimum ratios of 1.6-3.3 (Anders 2005). This indicates that the gauges must be able to resolve a difference in precipitation of $\sim 50 \%$.

Several methods were used to evaluate the quality of the gauge data we collected. At three sites we placed two rain and snow gauges next to each other to determine the reproducibility of the measurements. The difference in daily totals between gauges at the same site was within $20 \%$ at all three sites and for all days of record. For the majority of days $(\sim 70 \%)$ the difference in daily totals between twin gauges was within $10 \%$.

\footnotetext{
${ }^{1}$ Instead of relying upon the antifreeze for the third season, we depended only on the thermal inertia of the water in the reservoir to prevent freezing during the short periods of subzero temperatures that occur at our gauge sites. During a period of weeks in the midwinter the gauges did freeze, but we assumed that the majority of the frozen precipitation eventually melted and was recorded. Furthermore, collocated temperature data allowed us to identify times when freezing of the gauge reservoir may have been a problem, and we avoided using gauge data from these times for analysis in our case studies.
}

The rain-only gauges were calibrated in the laboratory and are accurate to within $\sim 12 \%$ with error increasing with rain rate. At one site a rain-only and a rain and snow gauge were established. The rain-only gauge measured $18 \%$ more precipitation than the rain and snow gauge for the overlapping period of record, suggesting significantly larger undercatch by the large rain and snow gauges. In addition, the rain-only gauge had a $0.2-\mathrm{mm}$ resolution, while the rain and snow gauges have 1-mm resolution. This bias between the rain-only gauges and rain and snow gauges would tend to make gauged estimates of the precipitation gradients smaller than they are in reality. This would suggest that the ridge-valley difference is at least as large, and may be larger than, what is recorded by the gauge network. Nevertheless, based on these estimates, we expect that the gauges are indeed able to resolve the gradients suggested by MM5.

Observed season totals for three winter seasons are shown in Fig. 3 along with the elevation at the gauge locations and the MM5 totals interpolated to the gauging sites for the period of record. Season total precipitation varies across the ridge, with ridge-valley ratios of 1.4, 1.3, and 1.3 for the 2003-04, 2004-05, and 2005-06 seasons, respectively. The maximum-minimum ratio was 1.6 for all three seasons. MM5 predictions for season totals match gauged precipitation remarkably well, both in terms of precipitation amount, and in the location and magnitude of spatial gradients in precipitation relative to topography (ridge-valley ratios of 1.4, 1.2, and 1.3; maximum-minimum ratios of $1.7,1.5$, and 1.5). ${ }^{2}$ Root-mean-squared error (RMSE) of the MM5 forecasts versus gauged precipitation were 285, 237, and $296 \mathrm{~mm}$ in the 2003-04, 2004-05, and 2005-06 seasons, respectively. This is about $10 \%$ of the mean gauged seasonal total precipitation in each season.

MM5 overpredicted precipitation on the NW (lee) side of the ridge in the 2003-04 season, while underpredicting in this region during the 2004-05 and 200506 seasons (Fig. 3). The change from simple ice microphysics in the first season to the Reisner 2 scheme in the second may be related to this change in model performance. Colle et al. (2005) found that as the simple ice physics overpredicted leeside precipitation more strongly than Reisner 2 microphysics for a case study in the Oregon Cascades as part of the second Improvement of Microphysical Parameterization through Ob-

\footnotetext{
${ }^{2}$ As shown in Fig. 3, the peak in topography resolved by the MM5's 4-km grid is 31\% lower and shifted $5 \mathrm{~km}$ to the northwest of the actual topography along the transect occupied by our gauges. Poor resolution of the terrain may contribute to model error.
} 

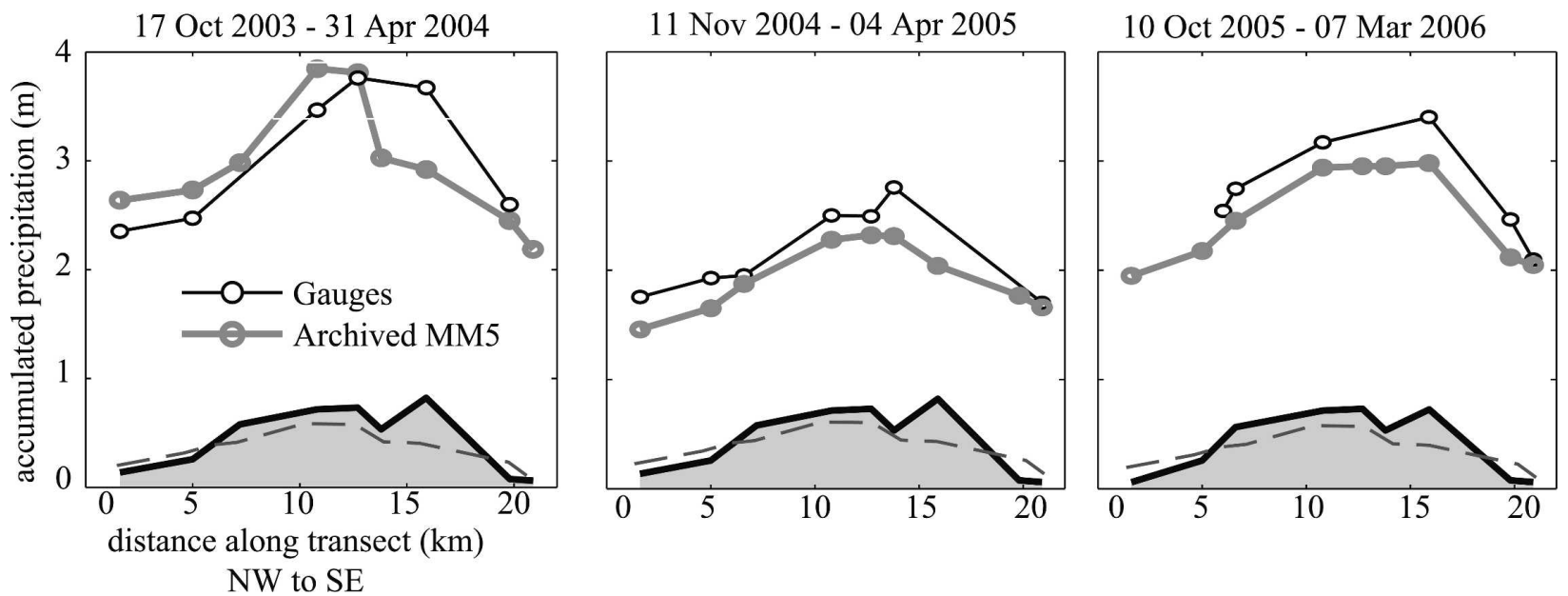

FIG. 3. Accumulated precipitation from gauges is shown as the black solid lines with circles indicating the locations of gauges. Gray lines are the MM5 precipitation forecasts for the gauge locations during the same time periods. A profile of the observed topography is shaded in gray; maximum elevation along the profile is about $820 \mathrm{~m}$. The topography in the 4-km resolution MM5 is shown by the dashed line.

servational Verification Experiment (IMPROVE 2) campaign. However, the gauges are located at relatively low elevation on the windward side of the range where the freezing level is often above the topography during large events. Thus, ice processes may be less important here at the gauge sites than throughout the Olympic mountains more generally. The gauge network may not be very sensitive to changes in MM5's microphysical scheme for this reason. Initial comparison of events run with simple ice versus Reisner microphysis and with $4-\mathrm{km}$ versus $4 / 3-\mathrm{km}$ resolution show smaller differences between models than the bias in all models relative to gauged precipitation (Minder et al. 2006).

In addition to long-term (annual or seasonal) totals in precipitation, we also present analysis of individual precipitation events measured in the gauge network and modeled with MM5. Each day in the 2003-04 gauging season was ranked according to the average daily precipitation totals across the gauge network from 0000 to 0000 UTC. In addition, the 10 largest 12 -h precipitation forecast totals from MM5 in the region of the gauge network were identified. The largest events of the season were defined using these largest 12-h measured or modeled precipitation periods as the starting point. We consider 12-h time periods before and after these starting points and include in the large events any 12-h time periods that meet one of the following conditions: either measured precipitation rates of $0.5 \mathrm{~mm}$ $\mathrm{h}^{-1}$ or greater were sustained into the 12 -h period, or 12-h forecast totals greater than $28 \mathrm{~mm}$ on average (one standard deviation above the mean for the season) were predicted. Thus, the large events are longer than $12 \mathrm{~h}$ each. This method of defining events ensured good overlap between the recorded and modeled event given possible mistiming of modeled frontal passages. In this process, 4 of the 10 largest measured precipitation periods were merged into 2 events, leaving 8 events with the largest measured totals. Likewise, the 10 largest 12-h forecasts collapse into 8 events. There is considerable overlap between the largest measured events and the largest modeled events: 6 events are members of both sets. In total, 10 events include the 10 largest measured or modeled 12-h precipitation periods of the 2003-04 season.

Cross sections of gauged precipitation and interpolated MM5 predictions at gauge locations for these events are shown in Fig. 4. In all cases, there is enhanced measured precipitation on the ridge relative to the valleys, but the magnitude of this difference varies considerably (ridge-valley and minimum-maximum ratios vary between 1.1 and 3.2; see Table 1) as does the location of the maximum precipitation value on the ridge. The majority of cases share several characteristics: a precipitation maximum toward the southeastern end of the ridge transect, at a position of $12-15 \mathrm{~km}$; similar values of precipitation in the two valleys; and steeper gradients in precipitation at the southern end of the ridge than at the northern end.

As shown in the lower right panel of Fig. 4, MM5 neither systematically over- nor underpredicts the total gauged precipitation for the 10 largest events. Rather, it under- or overpredicts for a few cases, and provides a very reasonable prediction for the remaining events. MM5 predicts similar enhancements of precipitation on the ridge relative to the valley as are seen in the gauge data (Table 1). The spatial pattern of precipitation over 

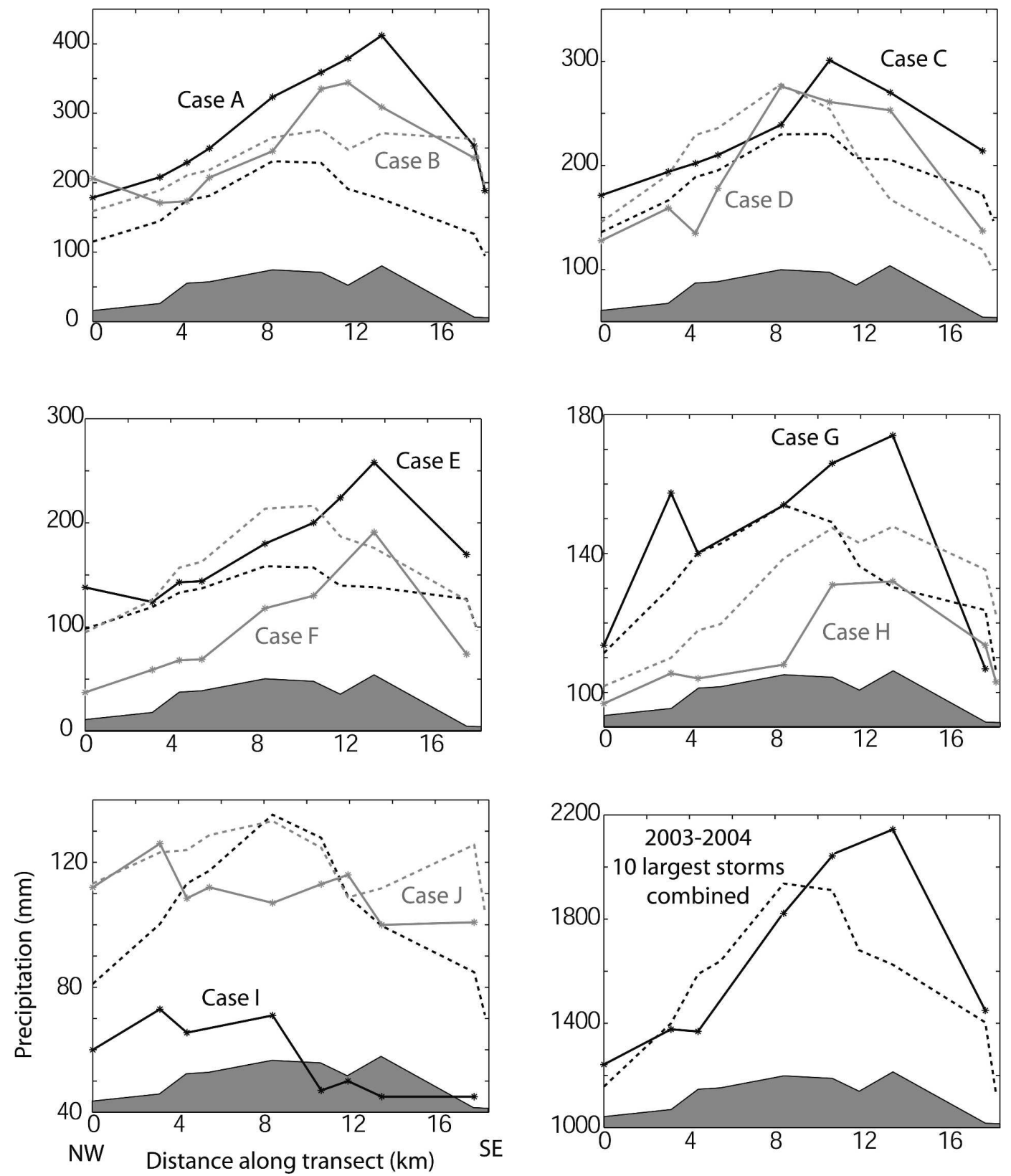

FIG. 4. For each of the 10 largest events of 2003-04, gauged measurements are shown as solid lines with stars indicating the position of operational gauges along the transect. Dashed lines in corresponding colors are the MM5 forecasts at the gauge locations for the same time periods. (lower right) The combined gauged and forecast precipitation for these large events. Details of the events are given in Table 1.

the ridge is more constant from storm to storm in MM5 than in the gauge record and the maximum precipitation tends to occur near the center of the ridge. The fit for the sum of the 10 events is better than the relative fit for most individual events with a RMSE of $226 \mathrm{~mm}$ or $14 \%$ of the gauged average (cf. to individual event errors in Table 1).
The events described above have gradients in precipitation similar to the seasonal totals shown in Fig. 3. The large events resemble the seasonal pattern, but account for only about $50 \%$ of the precipitation measured for the season, indicating that smaller events must also produce the same pattern of precipitation, on average. 


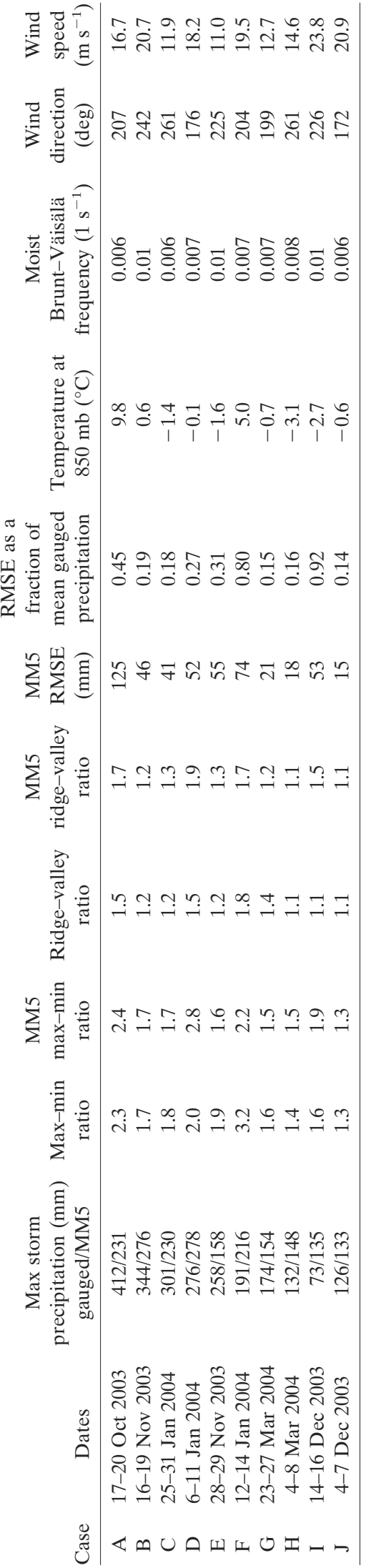

The horizontal distribution of the MM5 precipitation field for each of the 10 events is shown in Fig. 5. As the gauged events resemble the gauged season totals, the modeled pattern of precipitation for these events resembles the MM5 annual precipitation pattern (Fig. 2). In particular, the enhancement of precipitation on the ridges relative to valleys on the western and southwestern sides of the range is evident in these storm events and in the annual pattern. The relatively dry area over the Elwha Valley is also present in these cases. As indicated in Table 1, the average winds between 850 and $500 \mathrm{mb}$ in the Quillayute soundings taken during these events vary in direction from southerly $\left(172^{\circ}\right)$ to westerly $\left(261^{\circ}\right)$ and in speed from 11.0 to $23.8 \mathrm{~m} \mathrm{~s}^{-1}$. While the precipitation amounts in different regions are influenced by wind direction, the location and sign of smallscale spatial gradients in precipitation are not very sensitive to these shifts in wind speed and direction as measured by the Quillayute sounding.

To summarize, gauge measurements and MM5 forecasts reveal large gradients in precipitation at spatial scales of $\sim 10 \mathrm{~km}$ that are stable over yearly, seasonal, and storm event time scales. The same pattern of precipitation is apparent in 6 water years from MM5 despite changes in the model physics options and year-toyear variations in the total rainfall (Fig. 2). The seasonal totals from three winter seasons in a small-scale rain and snow gauge network show consistent patterns with enhanced precipitation on Matheny Ridge relative to neighboring valleys. Precipitation gradients predicted by MM5 are similar in magnitude and location to those measured with the gauge network, giving us confidence in the ability of MM5 to model climatological patterns of precipitation in this region. In general, both measured and modeled large events of the winter season 2003-04 resemble one another and the season totals despite nontrivial variability in the wind speed and direction, temperature, and atmospheric stability of these events (Figs. 4 and 5; Table 1). This indicates that topography itself, which is constant from event to event, plays the dominant role in determining the spatial pattern of precipitation.

The MM5 climatology shows ridge-valley enhancement for other ranges in the Pacific Northwest (e.g., Vancouver Island, Washington, and Oregon Cascades and Oregon Coast Range), but a dearth of gauges prevents checking of these modeled features with measurements. MM5 may or may not perform as well at highelevation inland sites where cold microphysics are more important. We also expect that our findings might not hold true for ranges where in incident flow during storm is extremely variable or where convective storms dominate. 

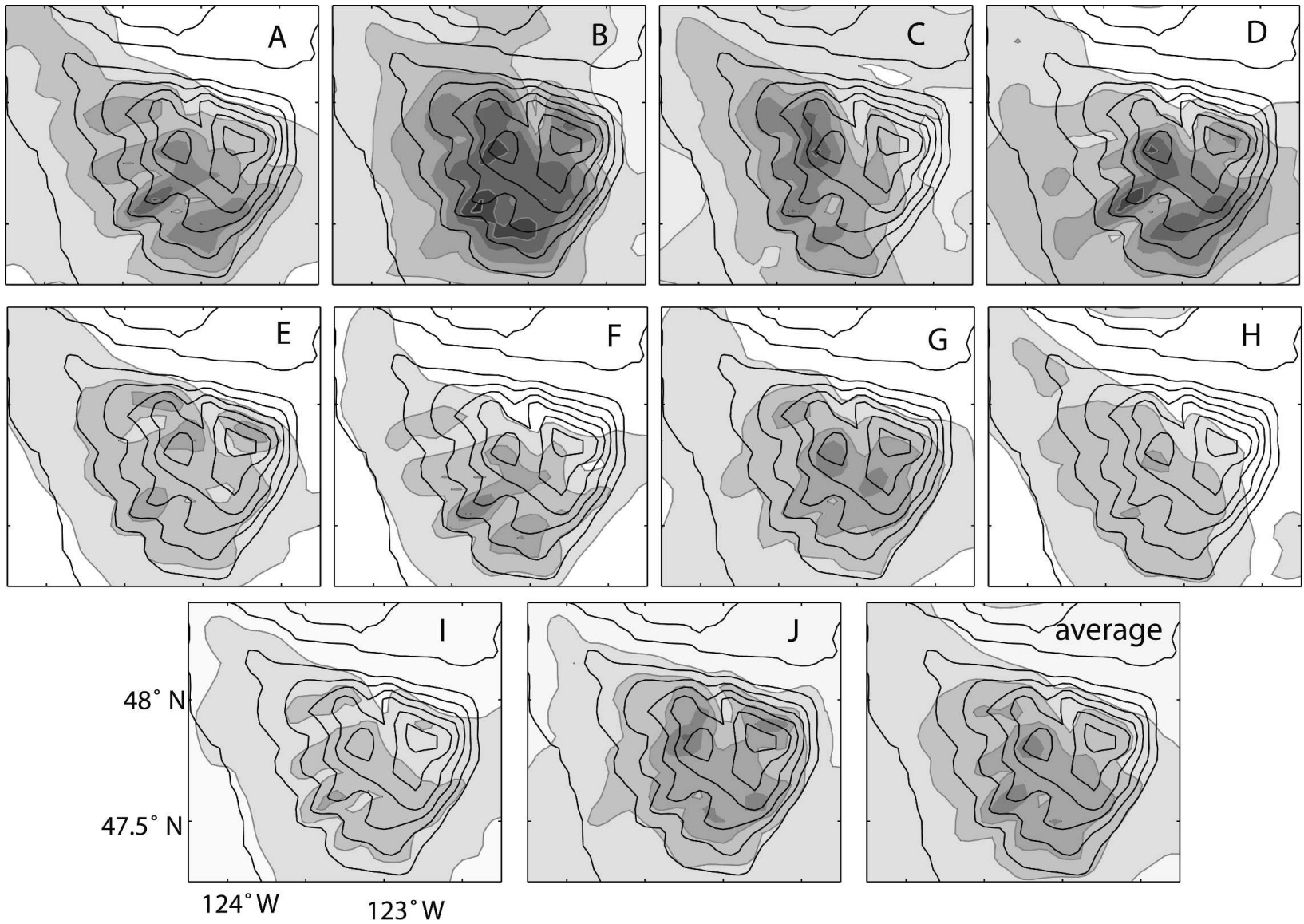

FIG. 5. The forecast precipitation for the 10 largest events is shown by gray shading and contoured at a 50-mm interval. Topography is contoured in black at a $250-\mathrm{m}$ interval.

\section{Simple models of precipitation in the Olympics}

On very long time scales, orographic precipitation is not only influenced by topography, it is also important in the evolution of topography. Erosion by rivers and glaciers, which is responsible for shaping the large-scale topography of mountain ranges, is dependent on accumulated precipitation in drainage basins (e.g., Hallet 1979, 1996; Oerlemans 1984; Harbor 1992; Howard 1994; Whipple 2004). The impact of billion-year-old rain shadows can be seen in the filling of sedimentary basins in eastern North America (Hoffman and Grotzinger 1993). Gradients in precipitation from India onto the Tibetan Plateau are hypothesized to control the spatial pattern of uplift of the Himalayas (Beaumont et al. 1992). At a smaller spatial scale, variations in precipitation within a drainage basin influence the maximum elevations, curvature of river profiles, and patterns of rock uplift in modeled actively uplifting mountain ranges (Roe et al. 2001, 2003; Anders 2005; Stolar et al. 2006).
Evaluating the impact of orographic precipitation patterns over geologic time scales of tens of thousands to tens of millions of years demands a computationally simple model. We therefore compare the precipitation patterns produced by MM5 and measured in our gauge network to those produced by a simple model of orographic precipitation described by Smith and Barstad (2004), hereafter referred to as the linear model. The linear model computes the steady-state linear mountain wave response to a uniform flow impinging on topography and the corresponding steady-state precipitation rate. A uniform horizontal wind speed and direction across the domain and uniform moist static stability are assumed throughout the moisture scale height of the atmosphere and the extent of the domain. The air is assumed to be saturated and temperatures follow saturated adiabats. The pattern of airflow over topography determines the location and extent of lifting. Under the saturated conditions, lifting initiates condensation of cloud water droplets. Formation of cloud droplets and precipitation is predicted for vertically integrated col- 
umns. Precipitation rates at the surface are modeled with two characteristic delay times, one representing the time required for the conversion of cloud droplets into precipitation particles and the other representing the time for these particles to fall out after formation, which enables the model to simulate the effect of advection of precipitation by the air motions. This linear model has previously been applied to the Olympic Mountains by Smith and Barstad (2004).

In this paper, the linear model is not meant to quantitatively predict the precipitation climatology. Rather, it is evaluated as a means of simulating the persistent precipitation gradients in mountainous topography. Thus, a defense of the linear model strictly applying to all conditions over the Olympic Mountains is not necessary for our purposes. For instance, nonlinear airflow may play a role in determining the precipitation pattern as blocking can reshape and displace precipitation maxima upstream over the windward side of a range (Jiang 2003), while flow splitting and leeside convergence are known to influence precipitation in the lee of the Olympics (Mass 1981). However, we note that the moist Froude number for the cases studied is near one-so that the airflow dynamics should be well represented by the linear solution. Although nonlinearities in the dynamics and microphysics no doubt play a role in precipitation, applying a linear model to the Olympics that neglects these effects offers a means of assessing their importance in determining the spatial distribution of climatological precipitation.

The parameters needed to run the linear model include the surface temperature, wind speed and direction, moist Brunt-Väisälä frequency, and the two delay times for condensation and fallout of precipitation. All of these parameters were estimated using radiosondes launched every $12 \mathrm{~h}$ from Quillayute, except for the delay times. The delay times were chosen in order to best match the spatial pattern of precipitation forecast by MM5 and the gauges. Estimated values of delay time range from 200 to $2000 \mathrm{~s}$ (Jiang and Smith 2003; Smith et al. 2005). We follow Smith and Barstad (2004) in setting the delay times equal to one another. For 20 large cases from the 2003-04 gauging season, fixed delay times of $800 \mathrm{~s}$ produce the best fits, both in terms of the spatial pattern of MM5's prediction and in terms of the ridge-valley differences observed in the gauge network (Anders 2005).

To explore the ability of the linear model to reproduce the spatial pattern of precipitation with sufficient fidelity for use in landscape evolution models, we used it to simulate the 10 large events from MM5 and the gauge record (Figs. 4 and 5; Table 1).

For each individual event, the Quillayute sounding launched nearest the time of maximum precipitation during the event provided the surface temperature, wind speed and direction, and moist Brunt-Väisälä frequency for the event. Wind speed and direction were defined as the average values between 850 and $500 \mathrm{mb}$. Moist Brunt-Väisälä frequency was calculated between these same pressure levels using an expression modified from Durran and Klemp [1982, Eq. (14)]:

$$
N_{m}^{2}=g\left(1+\frac{L q_{\mathrm{vs}}}{R T}\right)\left(1+\frac{\varepsilon L^{2} q_{\mathrm{vs}}}{c_{p} R T^{2}}\right)^{-1}\left(\frac{d \ln \theta}{d z}+\frac{L}{c_{p} T} \frac{d q_{\mathrm{vs}}}{d z}\right),
$$

where $N_{m}$ is the moist Brunt-Väisälä frequency, $g$ is gravity, $R$ is the gas constant for dry air, $c_{p}$ is the specific heat of dry air at constant pressure, $L$ is the latent heat of vaporization, $\theta$ is the potential temperature, $q_{\mathrm{vs}}$ is the saturation mixing ratio, $\varepsilon$ is $0.622, T$ is the temperature, and $z$ is in the vertical direction; $T$ is taken as the average temperature between 925 and $500 \mathrm{mb}$. The saturation mixing ratio is computed from the measured temperatures in this interval and averaged to estimate $q_{\mathrm{vs}}$. Vertical gradients of $q_{\mathrm{vs}}$ and $\theta$ are computed as the difference of the values between 925 and $500 \mathrm{mb}$ divided by the difference in heights of the pressure levels. A total delay time of $1600 \mathrm{~s}$ was used for each event. The linear model computes a steady-state precipitation rate in response to the boundary condition of steady uniform flow. Since there is no simple way to estimate the duration of each event, the rainfall rates computed with the linear model for the 10 largest storms (Table 1) were averaged and then scaled so that the maximum precipitation amount from the linear model matched the maximum average 10 -event precipitation total from the MM5.

The average precipitation computed by both models for these 10 large events is compared in Fig. 6. Both models produce similar precipitation patterns on the southwest and western sides of the Olympics, except at higher elevations, where the linear model generates significantly less precipitation. The linear model also fails to capture the precipitation in the lee, on the northeastern side of the massive. Nevertheless, the agreement between the MM5 and the linear models is excellent in the region of heavy precipitation along Matheny Ridge, and in both models, this ridge receives about $150 \%$ of the precipitation in the adjacent Queets Valley. In particular, the linear model and the MM5 agree very well along the cross section where our instruments were located (Fig. 6c).

The 10 largest cases in the gauge record and MM5 are shown individually as run by the linear model in Fig. 7. The spatial patterns of precipitation rate depicted in 

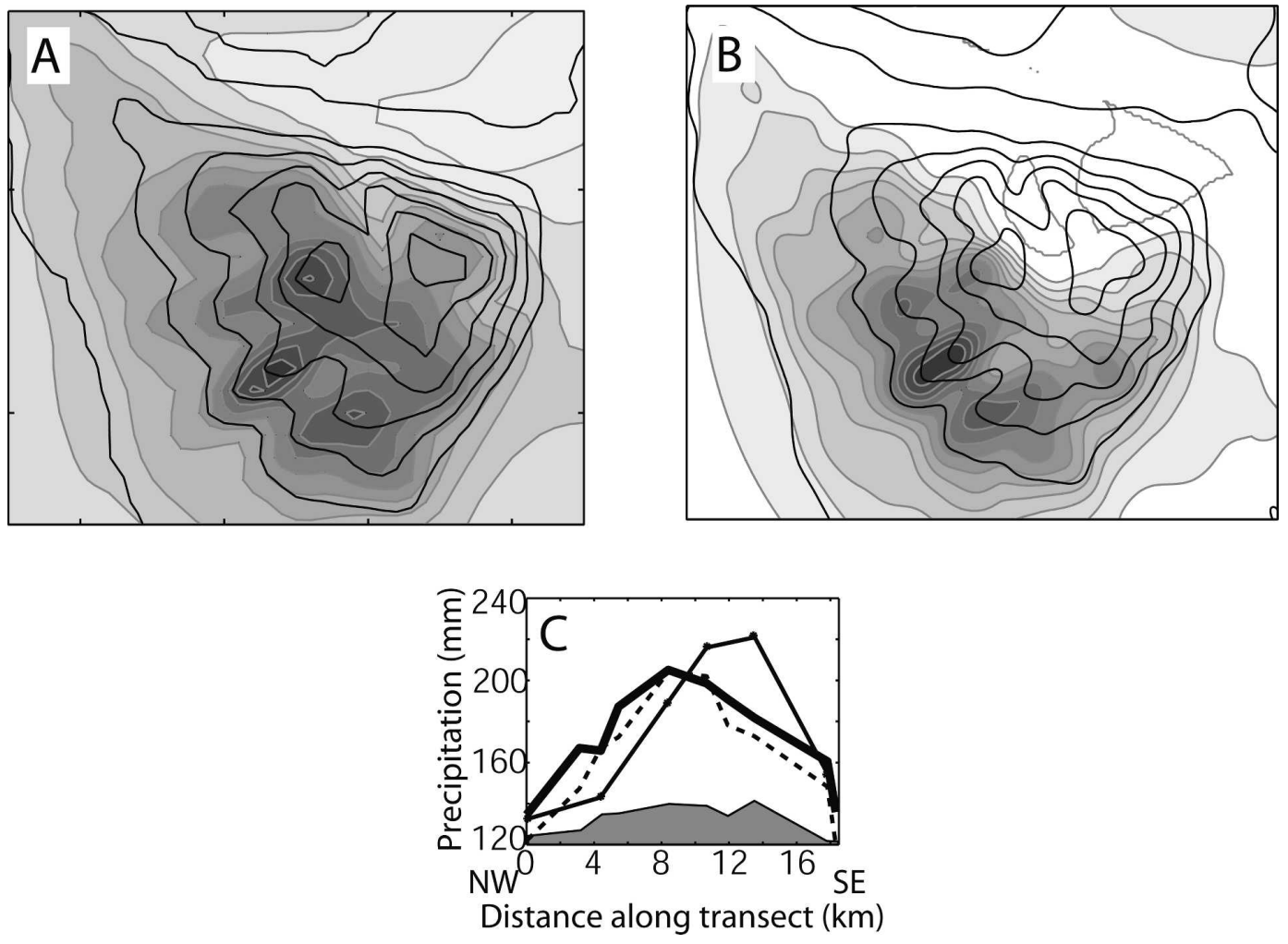

FIG. 6. Average precipitation per event for the 10 storms listed in Table 1. Shading at 20-mm contour intervals shows the precipitation from (a) the MM5 and (b) the linear model; the topography is contoured by the black lines at 250-m intervals. (c) The average observed precipitation for the same 10 events at the gauges (thin line with stars marking gauge locations) compared with the results from the MM5 (dashed line) and the linear model (thick solid line) along the same transect.

Fig. 7 can be compared to the MM5 forecasts for the same events in Fig. 5. In cases A, D, and F, and to a lesser extent $\mathrm{B}, \mathrm{G}$, and $\mathrm{I}$, the linear model produces gradients in precipitation rate that are similar to the gradients of precipitation in the corresponding MM5 forecasts. In other cases, especially $\mathrm{E}$ and $\mathrm{J}$, the linear model is not similar to the MM5 forecasts.

The spatial extent of the precipitation is less widespread in the linear model than in the MM5 because all precipitation in the linear model is driven by orographic lifting, while precipitation in MM5 can result from larger-scale lifting due to other dynamical effects. Additionally, MM5 has the flexibility to account for spatial and temporal variability in moisture content, wind speed and direction, and temperature, while these are all uniform in space and fixed in time in the linear model, and the conditions at the time of the Quillayute sounding may not be representative of average conditions during each event. The average of all 10 events in the linear model does, nevertheless, look similar to the 10-event average from MM5 (Fig. 6), suggesting that the linear model better represents long-term averages than individual events.
The linear model average of the large events is also similar in pattern to the 6-yr average of MM5 water years in terms of the windward side precipitation gradients. This indicates that linear atmospheric dynamics with a fixed delay time provides, at least, a good empirical fit to the MM5 climatology on the windward side. Although the ridge-valley gradient in precipitation appears to be adequately captured by the linear model, we cannot rule out the possibility that additional mechanisms play a role, especially in the variability in the precipitation pattern from storm to storm. Ongoing efforts to diagnose important physical processes suggest that wind shear and localized rapid conversion of cloud water to precipitation via collection processes are important in enhancing precipitation over ridges in the Olympics and the Oregon Cascades (Garvert et al. 2007).

\section{Discussion and conclusions}

This study has demonstrated that significant smallscale $(\sim 10 \mathrm{~km})$ climatological gradients in precipitation occur on the southwest side the Olympic Mountains. These gradients are similar to those documented in the 

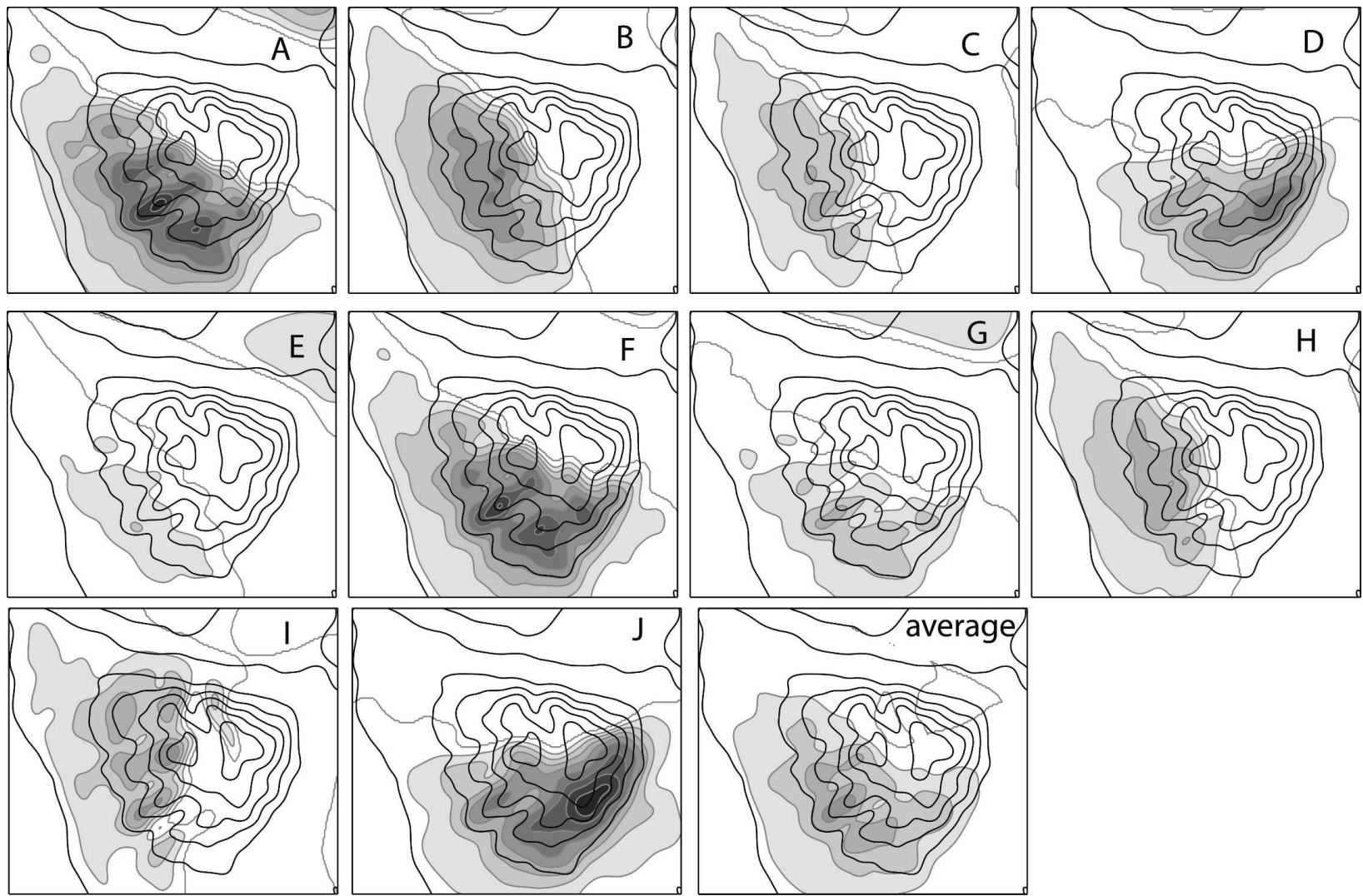

FIG. 7. Each of the 10 largest cases as simulated with the linear model is shown with $0.75 \mathrm{~mm} \mathrm{~h}^{-1}$ contours of precipitation rate in gray. Topography is contoured in black at a $250-\mathrm{m}$ interval.

Alps (Frei and Schär 1998) and the Himalayas (Barros et al. 2000; Anders et al. 2006). In the Olympics, the tendency for more precipitation on ridges relative to valleys is stable over a range of time scales from hours to years. Similarly, in the Alps and the Himalayas, small-scale precipitation patterns are persistent over time scales of years to decades (Frei and Schär 1998; Anders et al. 2006). While further investigation of the nature and persistence of small-scale precipitation patterns in other mountain ranges is warranted, it seems likely that small-scale climatological gradients in precipitation are a common feature of mountain climates.

Although at the annual time scale, the gauged and modeled precipitation pattern is quite stable, there is more variability in the location and amplitude of the precipitation maxima for 2-5-day events (Fig. 4). One likely source of this variability is changes in the freezing level and associated changes in the characteristic advection distance of precipitation particles, and is the subject of ongoing research (Minder et al. 2006). Other sources of variability in the pattern of precipitation between individual events include changes in the degree of blocking (Sinclair et al. 1997) and variations in the mean wind speed and direction (Hill et al. 1981).
We have compared the predictions of MM5 with rain and snow gauge measurements from a finescale network established at Matheny Ridge, in the Olympic Mountains. MM5 predicts amounts and spatial gradients in precipitation at the seasonal time scale that are very similar to those measured by the gauge network (Fig. 3). When compared at the event time scale, MM5's performance relative to the gauges is variable. As seen in Fig. 4, MM5 over- or underpredicts for several of the large events, while matching the observations closely for others. When the 10 large events are aggregated (Fig. 4), MM5 reproduces the observations nearly as well as in the season totals (Fig. 3). These results show that MM5 does not have a systematic bias in this region. We suggest that inability to accurately provide the large-scale initial and boundary conditions (from over the data-sparse Pacific Ocean) in cases where heavy precipitation may occur, limits the ability of MM5 to simulate the weather in these cases.

A change in resolution of MM5 from 4 to $1.33 \mathrm{~km}$ improved simulation of mesoscale features, but not precipitation bias scores in a case study from the Oregon Cascades during the IMPROVE 2 campaign (Garvert et al. 2005a). Two cases for our region, cases $\mathrm{A}$ and $\mathrm{E}$, 
were run at the $1.33-\mathrm{km}$ resolution and produced a similar pattern of precipitation with slightly better agreement with observed precipitation as compared with the operational 4-km resolution run. Our study has focused on climatological precipitation patterns rather than the simulation of individual precipitation events; therefore, we are limited to the resolution of the operational MM5 runs. The relatively good agreement between MM5 seasonal precipitation totals and observations suggests that the 4-km resolution may be sufficient for determining the climatological pattern of precipitation in the region of our gauge network: the lower windward slopes of the Olympic Mountains.

Changes in the microphysical scheme do not drastically change the pattern of the annual forecast precipitation, as can be seen in the comparison of water years 2004 and 2005 to previous years in Fig. 2. The change from simple ice physics to Reisner 2 physics in February 2004 does not create a large change in the error of MM5 relative to the gauges either from the 2003-04 season to the 2004-05 season (Fig. 3), or in the cases G and H, with Reisner 2 physics, relative to the other cases that had simple ice physics (Fig. 4). However, there is a change in the sign of the error in on the northwest side of Matheny Ridge from overprediction in 2003-04 to underprediction in 2004-05 and 2005-06, which may be related to the change in microphysics. At the time scale of the precipitation events, neither the magnitude nor the sign of MM5 errors are correlated with the microphysical scheme, suggesting that forecast errors in MM5 precipitation for individual events in the vicinity of our observational network are more likely due to the inaccurate specification of the upstream flow than to problems in the microphysical modeling. The geography of the Olympic Mountains and location of our gauge network may be responsible in part for the consistency of the observed and modeled pattern on storm and seasonal time scales as well as the model's skill in reproducing the climatology. For the Olympics, wind speed and direction vary considerably between storms, but do so within a limited range. While freezing levels vary between and within major storms in our record, during the times of heaviest precipitation the freezing level is nearly always above the height of the ridge, increasing the importance of simpler warm microphysics in determining the precipitation distribution and perhaps making the precipitation totals more predictable.

A computationally simple linear model is able to reproduce the structure of the precipitation patterns forecast by MM5 for the windward side of the Olympic Peninsula (Fig. 6). The Olympic Peninsula may be better suited to this approach than other mountain ranges because of the consistency of the upstream conditions that produce precipitation, the dominance of stable stratiform precipitation, and the relatively low elevation of the range. The simplicity of the linear model and its capacity to reproduce some of the small-scale structure of precipitation patterns makes it a candidate for use in landscape evolution models, which provide the first steps toward understanding long-term interactions between precipitation and topography (Anders 2005). While more research is necessary to better constrain both the atmospheric and geomorphic processes represented by such models, initial results demonstrate the potential for significant feedbacks through which patterns of orographic precipitation coevolve with the underlying topography.

Acknowledgments. This work was funded by a seed grant from the Program on Climate Change at the University of Washington. The catchment tube system for the original set of 10 rain and snow gauges were built by Pascal Stork and made available to us by Clifford Mass at the University of Washington. Stephen Domonkos helped us to repair these gauges, improve the gauge design, and build additional rain and snow gauges. Rick Steed and David Ovens helped us with MM5 simulations and accessing the data archive. Thanks to Olympic National Park and Olympic National Forest for providing guidance in establishing gauges. Thanks also to the Amanda Park Motel for allowing a gauge to be placed on their property. Three anonymous reviewers provided thoughtful and constructive comments that greatly improved this paper.

\section{REFERENCES}

Anders, A. M., 2005: The co-evolution of precipitation and topography. Ph.D. dissertation, University of Washington, 248 pp. , G. H. Roe, B. Hallet, D. R. Montgomery, N. J. Finnegan, and J. Putkonen, 2006: Spatial patterns of precipitation and topography in the Himalaya. Tectonics, Climate, and Landscape Evolution: Geological Society of America Special Paper 398, S. D. Willett et al., Eds., Geological Society of America, 39-53.

Barros, A. P., and D. P. Lettenmaier, 1993: Dynamic modeling of the spatial distribution of precipitation in remote mountainous areas. Mon. Wea. Rev., 121, 1195-1214.

_ , and _- 1994: Dynamic modeling of orographically induced precipitation. Rev. Geophys., 32, 265-284.

_- M. Joshi, J. Putkonen, and D. W. Burbank, 2000: A study of the 1999 monsoon rainfall in a mountainous region in central Nepal using TRMM products and rain gauge observations. Geophys. Res. Lett., 27, 3683-3686.

Beaumont, C., P. Fullsack, and J. Hamilton, 1992: Erosional control of active compressional orogens. Thrust Tectonics, K. R. McClay, Ed., Chapman and Hall, 1-18.

Bond, N. A., and Coauthors, 1997: The Coastal Observation and Simulation with Topography (COAST) experiment. Bull. Amer. Meteor. Soc., 78, 1941-1955. 
Caracoana, R., and J. W. Enz, 2000: An enhanced technique for a more reliable daily snow measurements with an antifreezebased tipping bucket gauge. Proc. Western Snow Conf. 68th Annual Meeting, Port Angeles, WA, Western Snow Conference, 87-91.

Colle, B. A., and C. F. Mass, 1996: An observational and modeling study of the interaction of low-level southwesterly flow with the Olympic Mountains during COAST IOP 4. Mon. Wea. Rev., 124, 2152-2175.

—, - and B. F. Smull, 1999: An observational and numerical study of a cold front interacting with the Olympic Mountains during COAST IOP5. Mon. Wea. Rev., 127, 1310-1334.

— - - - and K. J. Westrick, 2000: MM5 precipitation verification over the Pacific Northwest during the 1997-99 cool seasons. Wea. Forecasting, 15, 730-744.

_ , M. Garvert, J. Wolfe, and C. F. Mass, 2005: The 13-14 December 2001 IMPROVE-2 event. Part III: Simulated microphysical budgets and sensitivity studies. J. Atmos. Sci., 62, $3535-3558$.

Dingman, S. L., 1994: Physical Hydrology. Macmillan, 575 pp.

Durran, D. R., and J. B. Klemp, 1982: On the effects of moisture on the Brunt-Väisälä frequency. J. Atmos. Sci., 39, 2152-2158.

Ferguson, S. A., S. Breyfogle, M. B. Moore, R. Marriott, and D. Judd, 1997: NWAC mountain weather. USDA Natural Resources Conservation Service, Climate Data Access Facility Rep., 40 pp.

Frei, C., and C. Schär, 1998: A precipitation climatology of the Alps from high-resolution rain gauge observations. Int. J. Climatol., 18, 873-900.

Garvert, M. F., B. A. Colle, and C. F. Mass, 2005a: The 13-14 December 2001 IMPROVE-2 event. Part I: Synoptic and mesoscale evolution and comparison with a mesoscale model simulation. J. Atmos. Sci., 62, 3474-3492.

— C. P. Woods, B. A. Colle, C. F. Mass, P. V. Hobbs, M. T. Stoelinga, and J. B. Wolfe, 2005b: The 13-14 December 2001 IMPROVE-2 event. Part II: Comparisons of MM5 model simulations of clouds and precipitation with observations. $J$. Atmos. Sci., 62, 3520-3534.

_ B. Smull, and C. Mass, 2007: Multiscale mountain waves influencing a major orographic precipitation event. J. Atmos. Sci., 64, 711-737.

Groisman, P. Ya., and D. R. Legates, 1994: The accuracy of United States precipitation data. Bull. Amer. Meteor. Soc., 75, 215-227.

Hallet, B., 1979: A theoretical model of glacial abrasion. J. Glaciol., 17, 209-222.

_ 1996: Glacial quarrying: A simple theoretical model. Ann. Glaciol., 22, 1-8.

Harbor, J. M., 1992: Application of a general sliding law to simulating flow in a glacier cross section. J. Glaciol., 38, 182-190.

Hill, F. F., K. A. Browning, and M. J. Bader, 1981: Radar and raingauge observations of orographic rain over south Wales. Quart. J. Roy. Meteor. Soc., 107, 643-670.

Hoffman, P. F., and J. P. Grotzinger, 1993: Orographic precipitation, erosional unloading, and tectonic style. Geology, 21, 195-198.

Howard, A. D., 1994: A detachment limited model of drainage basin evolution. Water Resour. Res., 30, 2261-2285.

Jiang, Q., 2003: Moist dynamics and orographic precipitation. Tellus, 55A, 301-316.

— , and R. B. Smith, 2003: Cloud timescales and orographic precipitation. J. Atmos. Sci., 60, 1543-1559.

Leung, L. R., and Y. Qian, 2003: The sensitivity of precipitation and snowpack simulations to model resolution via nesting in regions of complex terrain. J. Hydrometeor., 4, 1025-1043.

Mass, C. F., 1981: Topographically forced convergence in western Washington State. Mon. Wea. Rev., 109, 1335-1347.

, and Coauthors, 2003: Regional environmental prediction over the Pacific Northwest. Bull. Amer. Meteor. Soc., 84, 1353-1366.

McCaughey, W. W., and P.E. Farnes, 1996: Measuring winter precipitation with an antifreeze-based tipping bucket gauge. Proc. Western Snow Conf. 64th Annual Meeting, Bend, OR, Western Snow Conference, 130-136.

Minder, J. R., A. M. Anders, D. Durran, and G. H. Roe, 2006: Small-scale gradients in climatological precipitation on the Olympic Peninsula. Extended Abstracts, 12th Conf. on Mountain Meteorology, Santa Fe, NM, Amer. Meteor. Soc., 4.5.

Oerlemans, J., 1984: Numerical experiments of large scale glacial erosion. Z. Gletcherkunde Glazial Geol., 20, 107-126.

Parsons, D. B., and P. V. Hobbs, 1983: The mesoscale and microscale structure and organization of clouds and precipitation in midlatitude cyclones. IX: Some effects of orography on rainbands. J. Atmos. Sci., 40, 1930-1949.

Roe, G. H., 2005: Orographic precipitation. Annu. Rev. Earth Planet. Sci., 33, 645-671.

- D. R. Montgomery, and B. Hallet, 2001: Effects of orographic precipitation variations on the concavity of steadystate river profiles. Geology, 30, 143-146.

,$- \ldots$, and — 2003: Orographic precipitation and the relief of mountain ranges. J. Geophys. Res., 108, 2315, doi:10.1029/ 2001JB001521.

Sinclair, M. R., D. S. Wratt, R. D. Henderson, and W. R. Gray, 1997: Factors affecting the distribution and spillover of precipitation in the Southern Alps of New Zealand-A case study. J. Appl. Meteor., 36, 428-442.

Smith, R. B., 1979: The influence of mountains on the atmosphere. Advances in Geophysics, Vol. 21, Academic Press, $87-233$.

_ and I. Barstad, 2004: A linear theory of orographic precipitation. J. Atmos. Sci., 61, 1377-1391.

,-- , and L. Bonneau, 2005: Orographic precipitation and Oregon's climate transition. J. Atmos. Sci., 62, 177-191.

Stolar, D. B., S. D. Willett, and G. H. Roe, 2006: Tectonic and erosional forcing of a critical orogen. Tectonics, Climate, and Landscape Evolution: Geological Society of America Special Paper 398, S. D. Willett et al., Eds., 241-250.

Thomas, B. E., L. A. Goodman, and T. D. Olsen, 1999: Hydrogeologic assessment of the Sequim-Dungeness area, Clallam County, Washington. USGS Water Resources Investigation Rep. 99-4048, 165 pp.

Westrick, K. J., and C. F. Mass, 2001: An evaluation of a highresolution hydrometeorological modeling system for the prediction of a cool-season flood event in a coastal mountainous watershed. J. Hydrometeor., 2, 161-180.

Whipple, K. X., 2004: Bedrock rivers and the geomorphology of active orogens. Annu. Rev. Earth Planet. Sci., 32, 151-185.

Wilson, W. T., 1954: Analysis of winter precipitation observations in the cooperative snow investigations. Mon. Wea. Rev., 82, 183-199.

Yang, D., B. E. Goodison, J. R. Metcalfe, V. S. Golubev, R. Bates, T. Pangburn, and C. L. Hanson, 1998: Accuracy of NWS 8" standard nonrecording precipitation gauge: Results and application of WMO intercomparison. J. Atmos. Oceanic Technol., 15, 54-68. 